\title{
Tamoxifen For Breast Cancer Chemoprevention: Low Uptake by High-Risk Women After Evaluation of a Breast Lump
}

\author{
Rebecca Taylor, MD, MSc ${ }^{1}$ \\ Kennetb Taguchi, MD, MDCM ${ }^{2}$ \\ 'Division of General Surgery, University \\ of Ottawa, Ottawa, Ontario, Canada \\ ${ }^{2}$ Division of General Surgery, Queen's \\ University, Kingston, Ontario, Canada
}

Sh

MORE ONLINE

www.annfammed.org
Conflicts of interest: none reported

\section{CORRESPONDING AUTHOR}

Rebecca Taylor, MD, MSc

\#1-35 Rosebery Ave

Ottawa, Ontario

K1S 1 W 1

beccaanntaylor@hotmail.com

\begin{abstract}
PURPOSE The Breast Cancer Prevention Trial (BCPT) published results in 1998 showing that the use of tamoxifen in high-risk women reduced the incidence of invasive breast cancer by $49 \%$. We examined the clinical impact of the BCPT to determine whether high-risk women informed of these results would use tamoxifen for chemoprophylaxis and to investigate the factors influencing this decision.

METHODS Of 345 women evaluated for a breast lump at a referral center, 89 were defined as high risk for but did not currently have cancer. These women were contacted about their elevated risk and informed that there exists a medication proved to reduce this risk. They were encouraged to discuss the issue with their family physician, to whom we sent copies of the 3 largest tamoxifen chemoprevention studies, including the BCPT. Follow-up was conducted by telephone to determine each woman's choice regarding tamoxifen use for chemoprevention and to ascertain her reasons for reaching this decision.
\end{abstract}

RESULTS Of the 89 high-risk women, 1 decided to take tamoxifen for breast cancer chemoprevention. Only 48 women discussed tamoxifen with their family physician; in 3 cases (3.4\%) the family physician recommended that the patient start taking tamoxifen, in 8 cases $(9.1 \%)$ the family physician made no recommendations, and in 37 cases (42\%) the family physician advised against tamoxifen. The most frequently cited factors influencing the decision not to start tamoxifen were a fear of adverse events (46.8\%), the family physician's recommendation (31.9\%), and a perceived low breast cancer risk (34\%).

CONCLUSION Family physicians recommended prophylactic tamoxifen to few women and even fewer women chose to take it. The major barrier appears to be concern about potential adverse effects of tamoxifen.

Ann Fam Med 2005;3:242-247. DOI: 10.1370/afm.284.

\section{INTRODUCTION}

n September 1998 the National Surgical Adjuvant Breast and Bowel

Project published results from the Breast Cancer Prevention Trial

(BCPT) showing that the use of tamoxifen in high-risk women reduced the incidence of invasive breast cancer by $49 \% .^{1}$ This significant reduction in risk led the US Food and Drug Administration (FDA) and Health Canada to approve the use of tamoxifen for breast cancer risk reduction among similar patients. This FDA approval represented the first ever of an agent for cancer risk reduction. ${ }^{2}$

There exists concern about the widespread use of tamoxifen for chemoprophylaxis because tamoxifen has several important side effects, including an increased incidence of endometrial cancer, deep vein thrombosis, 
pulmonary embolism, and stroke. Several expert bodies, including the American Society of Clinical Oncology and the Oncological Drug Advisory Committee, have recommended that tamoxifen should be offered to high-risk women in consultation with their physicians after a discussion of the potential risks and benefits. ${ }^{3}$ The impact of the FDA approval of tamoxifen on clinical practice is not known. This descriptive study of high-risk women seen in a tertiary-care clinic in Kingston, Ontario, Canada, was designed to determine whether these women are choosing to take tamoxifen for chemoprophylaxis and to investigate the factors influencing this decision.

\section{METHODS}

This study describes the results of a systematic risk assessment and consultation by a single general surgeon. From April 1, 1999, to March 31, 2001, all women seen for breast assessment by the senior author at the Hotel Dieu Hospital in Kingston, Ontario, were asked to complete a questionnaire that enabled an estimation of their lifetime and 5-year risk of developing breast cancer. The variables ascertained by the questionnaire and used for the subsequent estimation of risk were based on the multivariate logistic regression model developed by Gail et al. ${ }^{4}$ The definition of high risk was at least a $1.6 \%$ risk of invasive breast cancer in the next 5 years, the same as that used in the National Surgical Adjuvant Breast and Bowel Project BCPT. ${ }^{1}$ Of those surveyed, only women with a negative breast biopsy and who met the definition of high risk were included in the study. Women older than 80 years were excluded. Informed consent was obtained before the completion of the survey, and the Ethics Review Board at Queen's University, according to the Tri-Council Guidelines, approved the study.

Each of the 89 study participants was sent a letter outlining her estimated 5 -year and lifetime risk for developing invasive breast cancer and encouraging her to discuss taking tamoxifen for breast cancer prevention with her family physician. The family physician who had referred the patient was sent a consultation letter describing the breast cancer risk assessment and explaining that the patient was a candidate for chemoprevention with tamoxifen. For reference, each physician also received copies of the 3 published trials on primary prevention (the BCPT and 2 European trials that did not show the same beneficial effect of tamoxifen for breast cancer chemoprevention $)^{1,5,6}$ along with 3 published editorials. ${ }^{7.9}$ The letter specified that the surgeon made no specific recommendations with respect to tamoxifen chemoprevention.

All participants were contacted by telephone an average of 5.1 months (range of 49 days to 14.0 months) after delivery of the letter. In the follow-up survey, using closed-ended questions, participants were asked whether they had discussed the issue of tamoxifen for breast cancer chemoprevention with their family physician and whether their physician had recommended the use of tamoxifen to them. In addition, they were asked whether they had decided to take tamoxifen, and if not, what their reasons were for this decision. The reasons listed in the questionnaire were chosen after a review of the literature relating to tamoxifen use for secondary prevention and enrollment in the BCPT.

All data were collected and analyzed using Microsoft Excel 97, SR-1. The $\chi^{2}$ test was used to compare proportions. A risk-benefit model for tamoxifen chemoprophylaxis, ${ }^{10}$ published after the beginning of our study, was retrospectively applied to stratify participants into 3 groups: those with strong, moderate, or no evidence for net benefit of tamoxifen according to the variables in the model.

\section{RESULTS}

\section{Study Population}

Of the 345 women seen in our clinic for assessment of a breast lump, 114 (33\%) were defined as high risk for breast cancer. From this group 25 women were excluded (Figure 1). The study population consisted of 89 women, between 35-80 years old, at increased risk of breast cancer. The patient demographics are outlined in Table 1. Patients were retrospectively classified into groups based on the evidence for a net benefit with tamoxifen use, ${ }^{10}$ as shown in Figure 1.

\section{Survey Results}

The follow-up questionnaire was completed by 88 of the 89 women. The study patients were referred from 65 different family physicians. Forty (45.4\%) women surveyed did not discuss the issue of taking tamoxifen with their family physician, and none of these women started taking tamoxifen. Of the 48 women who did discuss tamoxifen with their family physician, the physician recommendation, the decision to take tamoxifen, and the factor(s) influencing their decisions are outlined in Table 2. There was no relationship between the follow-up interval and the proportion of women who discussed the issue of chemoprevention with their family physician $\left(\chi^{2}{ }_{3}=3.3, P=.4\right)$.

Only 1 woman who participated in the study decided to start taking tamoxifen for breast cancer prevention. This woman was 75 years old and had a projected 5-year breast cancer risk of $2.0 \%$; therefore, she would be unlikely to experience a net benefit from tamoxifen therapy according to the risk-benefit algorithm. ${ }^{10}$ Five women started taking raloxifene after 


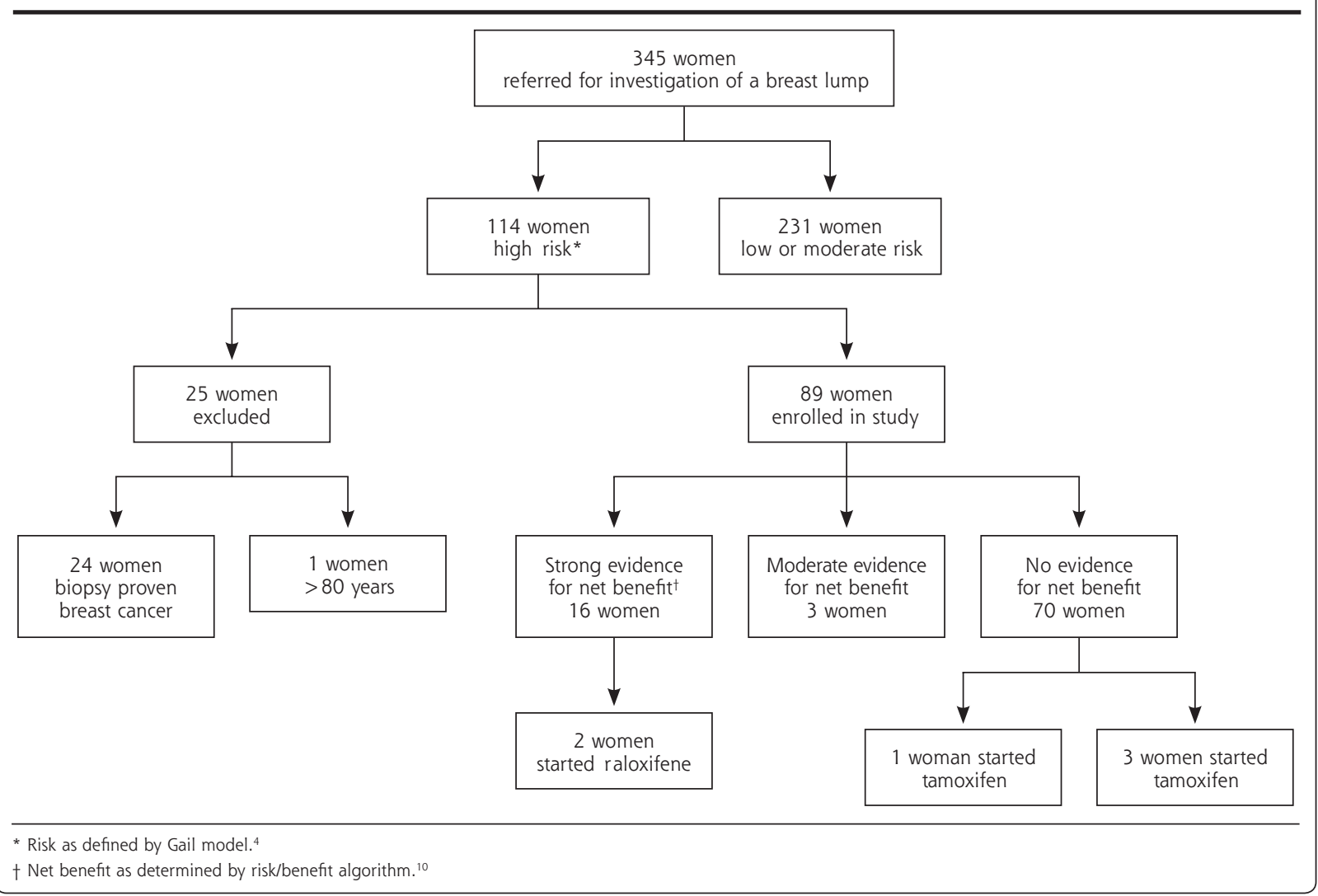

notification of their breast cancer risk (Figure 1). In all 5 cases the women were postmenopausal, and osteopenia or osteoporosis was their primary indication for receiving raloxifene; breast cancer risk reduction was described to them by their family physician as a secondary benefit of this medication.

\section{DISCUSSION}

Since the release of the BCPT results in 1998, there has been considerable debate over how to interpret these results and when to recommend tamoxifen for chemoprevention in high-risk women. Although the survey was done in Canada, we believe the results should be generalizable to the United States, because tamoxifen was approved for chemoprophylaxis and the results of the BCPT were similarly publicized in the 2 countries.

The overwhelming majority of high-risk women we surveyed (98.9\%) opted against taking tamoxifen. Fear of serious adverse effects, the perception of being at low risk, and the lack of physician recommendation were the 3 most frequently cited factors in the decision not to use tamoxifen. Daly et $\mathrm{al}^{11}$ previously noted that for $56 \%$ of women surveyed, concern about the side effects of tamoxifen affected their willingness to par- ticipate in the BCPT. Yeomans-Kinney et $\mathrm{al}^{12}$ also found that women who chose not to participate in the in the BCPT were significantly more likely than participants to report concern about the side effects of tamoxifen. At the Memorial Sloan Kettering Cancer Center, fear of side effects was found by Port et $\mathrm{al}^{13}$ to be the most common reason to decline tamoxifen among a group of high-risk women offered this chemoprevention.

Perceived susceptibility is also a significant predictor of preventive health behavior. ${ }^{14}$ In this study most patients $(55 \%)$ had a 5 -year predicted breast cancer risk of $1.6 \%$ to $2.0 \%$ and were, therefore, at the lower end of the high-risk spectrum. The effect on risk perception of having recently received a benign evaluation of a breast lump was not explored,

Only 3 out of 65 family physicians in our study recommended the use of tamoxifen. The family physician's opinion was cited as a key factor in the decision not to use tamoxifen for almost one third of our study participants. Numerous other studies have shown physician recommendation to be an important determinant of treatment decisions in the setting of hormone replacement therapy ${ }_{1}^{15-17}$ breast cancer adjuvant therapy ${ }_{1}^{18}$ and mammography screening. ${ }^{18}$ In a study of a subset of 360 women who discussed participation in the BCPT 


\begin{tabular}{|c|c|c|}
\hline Characteristic & No. & $\%$ \\
\hline \multicolumn{3}{|l|}{ Age, y } \\
\hline $40-49$ & 11 & 12 \\
\hline $50-59$ & 18 & 20 \\
\hline $60-69$ & 33 & 37 \\
\hline $70-80$ & 27 & 30 \\
\hline \multicolumn{3}{|l|}{ Menopausal status } \\
\hline Premenopausal & 16 & 18 \\
\hline Postmenopausal & 73 & 82 \\
\hline \multicolumn{3}{|l|}{ Previous hysterectomy } \\
\hline Yes & 35 & 39 \\
\hline No & 54 & 61 \\
\hline \multicolumn{3}{|c|}{ First degree relative(s) with breast cancer } \\
\hline Yes & 37 & 42 \\
\hline No & 52 & 58 \\
\hline \multicolumn{3}{|c|}{ History of atypical hyperplasia in the breast } \\
\hline Yes & 3 & 3 \\
\hline No & 86 & 97 \\
\hline \multicolumn{3}{|c|}{5 -year predicted breast cancer risk, ${ }^{4} \%$} \\
\hline$<2.00$ & 49 & 55 \\
\hline $2.01-3.00$ & 20 & 22 \\
\hline $3.01-5.00$ & 15 & 17 \\
\hline$>5.00$ & 5 & 5 \\
\hline \multicolumn{3}{|c|}{ Evidence for a net benefit with tamoxifen ${ }^{10}$} \\
\hline No evidence & 16 & 18 \\
\hline Moderate evidence & 3 & 3 \\
\hline Strong evidence & 70 & 79 \\
\hline Total & 89 & 100 \\
\hline
\end{tabular}

with their family physician, Yeomans-Kinney et al found that physician recommendation was the most important factor influencing a respondent's decision to enroll ${ }^{19}$ and women reporting that their family physician advised them to enroll in the trial were 13 times more likely to participate. One limitation of our study is that the family physicians were not contacted to ascertain their recollection of information from the consulting surgeon, as well as their knowledge and attitudes toward tamoxifen for chemoprophylaxis. Our data rely on the patients' interpretation of the interaction with her family physician, which may be subject to recall bias.

When does the benefit of breast cancer risk reduction outweigh the risk of adverse effects from tamoxifen use? The Supplemental Appendix (available online only at http://www.annfammed.org/ cgi/content/ $\nabla / r_{i}$ full/3/3/242/DC1 $)^{2,7-10,20-29}$ provides a summary of the trials evaluating tamoxifen and describes the published algorithm, ${ }^{10}$ developed by a panel of breast cancer experts, to weigh risks and benefits of breast cancer chemoprevention with tamoxifen. Using this algorithm stratifies patients according to a risk-benefit ratio and may facilitate patient counseling by physi-
Table 2. Physician Recommendation, Decision to Take Tamoxifen, and Factors Influencing This Decision Among 48 Women Who Discussed Taking Tamoxifen With Their Family Physician

\begin{tabular}{|c|c|c|}
\hline Question & No. & $\%$ \\
\hline \multicolumn{3}{|l|}{ Family physician recommendation } \\
\hline Recommended tamoxifen & 3 & 6 \\
\hline No recommendation & 8 & 17 \\
\hline Recommended against tamoxifen & 37 & 77 \\
\hline \multicolumn{3}{|l|}{ Women's decision } \\
\hline Take tamoxifen & 1 & 2 \\
\hline Not to take tamoxifen & 47 & 98 \\
\hline Total no. of women & 48 & 100 \\
\hline \multicolumn{3}{|l|}{ Factors influencing decision* } \\
\hline Fear of adverse effects ${ }^{\dagger}$ & 22 & 46 \\
\hline Risk not high enough & 16 & 33 \\
\hline Family physician's decision & 15 & 31 \\
\hline Personal decision & 12 & 25 \\
\hline Lack of sufficient data & 5 & 10 \\
\hline Total number of reasons & 70 & \\
\hline \multicolumn{3}{|c|}{$\begin{array}{l}\text { * Women were permitted to identify more than } 1 \text { factor influencing their deci- } \\
\text { sion to take tamoxifen; therefore, the number of reasons does not equal the } \\
\text { number of women. The percentage value indicates the number of women identi } \\
\text { fying that factor among the } 48 \text { women. } \\
\dagger \text { The specific adverse events of concern to respondents included thromboem- } \\
\text { bolic disease, uterine cancer, and such symptoms as hot flushes. }\end{array}$} \\
\hline
\end{tabular}

cians, allowing women to make an informed choice about the use of tamoxifen for breast cancer chemoprevention (Figure 2). When this algorithm was retrospectively applied to the women in our study, 4 women without a uterus and 12 women with a uterus were classified as likely to have a net benefit from tamoxifen. In addition, there was moderate evidence that 3 women without a uterus would benefit from tamoxifen (Figure 1). The only woman who chose tamoxifen chemoprophylaxis was retrospectively defined as unlikely to experience a net benefit from tamoxifen.

It is interesting to note that some physicians are recommending raloxifene rather than tamoxifen. ${ }^{25}$ In our study 5 women were prescribed raloxifene after notification of their elevated breast cancer risk, although in each case the primary indication was osteoporosis. Raloxifene has not been approved for primary breast cancer chemoprevention (for more information on the use of raloxifene for breast cancer chemoprevention refer to the Supplemental Appendix).

It is important to consider the societal implications of widespread tamoxifen use for high-risk women. In April 2003, the Journal of the National Cancer Institute published a study estimating the proportion of the female US population who could benefit from taking tamoxifen. ${ }^{30}$ The results indicate that although more than 10 million American women are eligible for tamoxifen based on the FDA approval guidelines, 2 million 
Figure 2. Classification of high-risk women by presence or absence of a uterus, age, and projected 5 -year risk of invasive breast cancer.
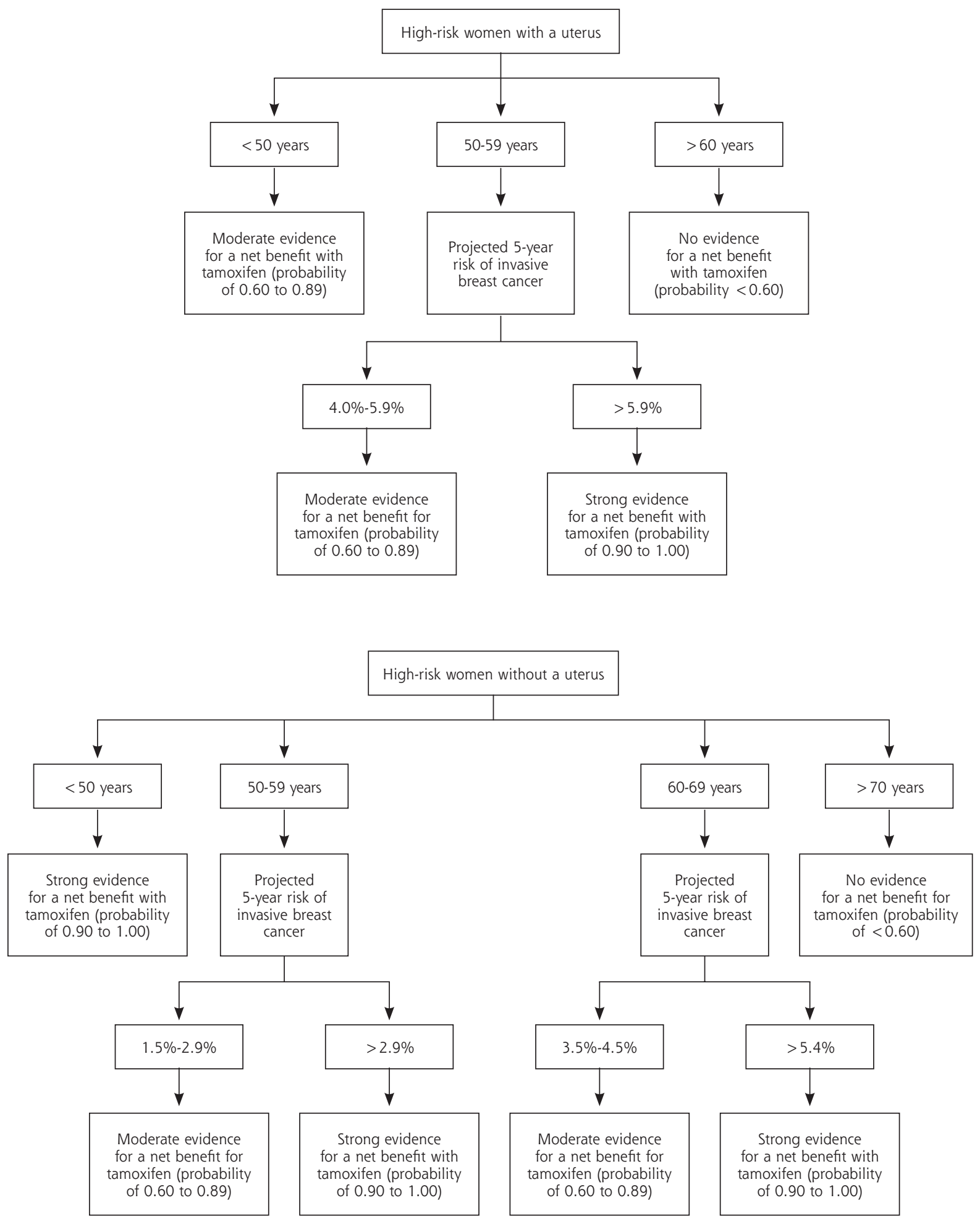

From Gail MH, Constantino JP, Bryant J, Croyle R, Freedman L, Helzlsouer K, Vogel V. Weighing the risks and benefits of tamoxifen treatment for prevention. J Natl Cancer Inst 1999;91:1829-1846. 
women have a favorable risk-benefit ratio as calculated by the Gail algorithm. ${ }^{10}$ If these 2 million women chose to take tamoxifen, 1 million breast cancers could be prevented in the United States in the next 5 years.

\section{To read commentaries or to post a response to this article, see it online at http://www.annfammed.org/cgi/content/full/3/3/242.}

Key words: Breast neoplasms; tamoxifen; anticarcinogenic agents; chemoprevention; BCPT trial

Submitted February 21, 2004; submitted, revised November 25, 2004; accepted December 2, 2004.

Preliminary results of this study were displayed in a poster presentation at the Canadian Association of General Surgery Annual Meeting, September 2001, Quebec City, Canada.

\section{References}

1. Fisher B, Costantino JP, Wickerham L, et al. Tamoxifen for prevention of breast cancer: report of the National Surgical Adjuvant Breast and Bowel Project P-1 study. J Natl Cancer Inst. 1998;90:1371-1388.

2. Lippman SM, Brown PH. Tamoxifen prevention of breast cancer; an instance of fingerpost. J Natl Cancer Inst. 1999;91:1809-1819.

3. Reynolds T. Tamoxifen debate hinges on whose risk is high enough. J Natl Cancer Inst. 1998;90:1428-1430.

4. Gail MH, Brinton LA, Byar DP, et al. Projecting individualized probabilities of developing breast cancer for white females who are being examined annually. J Natl Cancer Inst. 1989;81:1879-1886.

5. Veronesi $\mathrm{U}$, Maisonneuve P, Costa A, et al. Prevention of breast cancer with tamoxifen: preliminary findings from the Italian randomised trial among hysterectomised women. Lancet. 1998;352:93-97.

6. Powles T, Eeles R, Ashley S, et al. Interim analysis of the incidence of breast cancer in the Royal Marsden Hospital tamoxifen randomised chemoprevention trial. Lancet. 1998;352:98-101.

7. Goel V. Tamoxifen and breast cancer prevention: What should you tell your patients? CMAJ. 1998;158:1615-1617.

8. Margolese RG. How do we interpret the results of the Breast Cancer Prevention Trial? CMAJ. 1998;158:1613-1614.

9. Pritchard $\mathrm{KI}$. Is tamoxifen effective in prevention of breast cancer? (commentary) Lancet. 1998;352:80-81.

10. Gail MH, Constantino JP, Bryant J, et al. Weighing the risks and benefits of tamoxifen treatment for prevention. J Natl Cancer Inst. 1999;91:1829-1846.

11. Daly M, Seay J, Balshem A, Lerman C, Engstrom P. Feasibility of a telephone survey to recruit health maintenance organization members into a Tamoxifen chemoprevention trial. Cancer Epidemiol Biomarkers Prev. 1992;1:413-1416.

12. Yeomans-Kinney A, Vernon SW, Frankowski RF, Weber DM, Bitsura JM, Vogel VG. Factors related to enrollment in the breast cancer prevention trial at a comprehensive cancer center during the first year of recruitment. Cancer. 1995;76:46-56.
13. Port ER. Montgomery LL. Heert AS. Borgen PI. Patient reluctance towards tamoxifen use for breast cancer primary prevention. Ann Surg Onc 2001;8:580-585.

14. Janz NK. Becker MH. The health belief model: a decade later. Health Educ Q. 1984;11:1-47.

15. McNagny SE, Jacobsen TA. Use of postmenopausal hormone replacement therapy by African American women. The importance of physician discussion. Arch Intern Med. 1997;157:1337-1342.

16. Walsh JM, Brown JS, Rubin S, Kagawa M, Grady D. Post menopausal hormone therapy: factors influencing women's decision making Menopause. 1997;4:39-45.

17. Newton KM, Lacroix AZ, Leveille SG, Rutter C, Keenan NL, Anderson LA. The physician's role in women's decision making about hormone replacement therapy. Obstet Gynecol. 1998;92:580-584.

18. Skinner CS, Stretcher VJ, Hospers H. Physicians' recommendations for mammography: do tailored messages make a difference? Am J Public Health. 1994;84:43-49.

19. Yeomans Kinney a, Richards C, Vernon S, Vogel V. The effect of physician recommendation on enrollment in the breast cancer chemoprevention trial. Prev Med. 1998;27:713-719.

20. Vogel V. Breast cancer prevention: a review of current evidence. $C A$ Cancer J Clin. 2000;50:156-170.

21. Constantino JP, Gail MH, Pee D et al. Validation studies for models projecting the risk of invasive and total breast cancer incidence. J Natl Cancer Inst. 1999;91:1541-1548.

22. Spiegelman D, Colditz GA, Hunter D, Hertzmark E. Validation of the Gail et al. model for predicting individualized breast cancer risk. J Natl Cancer Inst. 1994;86:600-607.

23. IBIS Investigators. First results from the International Breast Cancer Intervention Study: a randomised prevention trial. Lancet. 2002:360:817-824

24. Fisher B. Highlights from recent National Surgical Adjuvant Breast and Bowel Project studies in the treatment and prevention of breast cancer. CA Cancer J Clin. 1999;49:159-177.

25. Brown P, Lippman S. Chemoprevention of breast cancer. Breast Cancer Res Treat. 2000;62:1-17.

26. King MC, Wieand S, Hale K, Lee $M$ et al. Tamoxifen and breast cancer incidence among women with inherited mutations in BRCA1 and BRCA2: National Surgical Adjuvant Breast and Bowel Project (NSABPP1) Breast Cancer Prevention Trial. JAMA. 2001;288:2251-2256.

27. Duffy SW, Nixon RM. Estimates of the likely prophylactic effect of tamoxifen in women with high risk BRCA1 and BRCA2 mutations. $\mathrm{Br} J$ Cancer. 2002;86:218-221.

28. Cummings SR, Eckert $S$, Lippman $M$, et al. The effect of raloxifene on risk of breast cancer in post-menopausal women: results from the MORE randomized trial. JAMA. 1999;281:2189- 2197.

29. Cauley JA, Norton L, Lippman ME, Eckert S, Krueger KA et al. Continued breast cancer risk reduction in postmenopausal women treated with raloxifene: 4-year results from the MORE trial. Breast Cancer Res Treat. 2001;65:125-134.

30. Freedman AN, Graubard BI, Rao SR, McCaskill-Stevens W, BallardBarbash R, Gail MH. Estimates of the number of US women who could benefit from tamoxifen for breast cancer chemoprevention. J Natl Cancer Inst. 2003;95:526-532. 